\title{
Grau de Transparência Pública nas Empresas Estatais do Sul do Brasil
}

\author{
http://dx.doi.org/10.21527/2237-6453.2020.51.129-146
}

Recebido em: 4/5/2019

Aceito em: 4/12/2019

\section{Márcia Bianchi, ${ }^{1}$ Sibely Rodrigues Machado, ${ }^{2}$ Vanessa Noguez Machado ${ }^{3}$}

\begin{abstract}
RESUMO
Esta pesquisa tem como objetivo analisar o grau de aderência aos requisitos de transparência e acesso à informação nos portais eletrônicos das empresas estatais pertencentes aos governos dos Estados do Rio Grande do Sul (RS), Paraná (PR) e Santa Catarina (SC). A partir de uma pesquisa quantitativa, descritiva e documental, foi possível evidenciar que as estatais do PR atingiram $76 \%$ de aderência à transparência, seguida pelas estatais do RS e de SC, com $64 \%$ e $62 \%$, respectivamente. Ainda, $68 \%$ da amostra observa as exigências requeridas para os sítios eletrônicos, sendo classificadas como de médio grau de aderência. Ainda não há, no entanto, aderência plena, nem mesmo alto grau de aderência para todos os indicadores analisados, demonstrando que a fiscalização dos portais eletrônicos precisa ser mais efetiva.
\end{abstract}

Palavras-chave: Transparência pública. Acesso à informação. Portais eletrônicos. Estatais.

\section{DEGREE OF PUBLIC TRANSPARENCY IN STATE COMPANIES OF THE SOUTHERN OF BRAZIL}

\section{ABSTRACT}

The objective of this research is to analyze the degree of adherence to transparency requirements and access to information in the electronic portals of the state-owned companies belonging to the states of Rio Grande do Sul (RS), Paraná (PR) and Santa Catarina (SC). From a quantitative, descriptive and documentary research, it was possible to show that the state-owned PR companies achieved $76 \%$ adherence to transparency, followed by RS and SC state, with $64 \%$ and $62 \%$, respectively. Still, $68 \%$ of the sample meets the requirements required for electronic sites, being classified as medium degree of adhesion. However, there is still no full adherence, nor even a high degree of adherence to all the analyzed indicators, demonstrating that the supervision of electronic portals needs to be more effective.

Keywords: Public transparency. Access to information. Electronic portals. State.

\footnotetext{
${ }^{1}$ Doutora em Economia do Desenvolvimento pela Universidade Federal do Rio Grande do Sul (UFRGS). Professora da Universidade Federal do Rio Grande do Sul (UFRGS). marcia.bianchi@ufrgs.br

${ }^{2}$ Graduada em Ciências Contábeis pela Universidade Federal do Rio Grande do Sul (UFRGS). sibely.rodriguesmachado@gmail.com

${ }^{3}$ Mestre em Controladoria e Contabilidade (UFRGS). Doutoranda em Ciências Contábeis pela Universidade Federal de Santa Catarina (UFSC). vanessa_nm93@hotmail.com
} 
A Administração Pública é o conjunto das normas, leis e funções desempenhadas para organizar a gestão do Estado em todas as suas instâncias e tem como principal objetivo o interesse público (BRASIL, 1988). De acordo com a identificação dos países membros da Organização das Nações Unidas (ONU), a integridade, transparência e responsabilidade são princípios fundamentais da Administração Pública, precisando ser adotados e vistos como praticados, gerando maior confiabilidade no desempenho de suas funções (ARMSTRONG, 2005). Nesse sentido, entende-se como papel da Administração satisfazer as necessidades da sociedade por meio da prestação de serviços, mas para que seu desempenho seja eficaz tornam-se necessárias boas práticas de gestão que correspondam ao interesse da social (CGU, 2011).

A transparência no setor público possibilita ao cidadão acompanhar informações atualizadas e obter conhecimento sobre os recursos públicos e sua aplicação (CGU, 2011), estando diretamente relacionada à disponibilização de um maior número de informações, bem como informações mais ricas, a respeito de sua eficiência e sua eficácia (REICHARD, 1998). Assim, para garantir uma gestão de qualidade na prestação de contas, os órgãos e entidades precisam disponibilizar informações transparentes e objetivas, de forma compreensível ao cidadão, uma vez que o acesso ao conteúdo público é um direito fundamental da sociedade e possibilita condições favoráveis para conhecer e acessar direitos e benefícios sociais que provêm somente da informação divulgada (CGU, 2011).

O direito da população em receber dos órgãos públicos as informações que lhes interessarem (BRASIL, 1988) é efetivado com a Lei n 12.527 (BRASIL, 2011b), conhecida como Lei de Acesso à Informação (LAI). Cabe ressaltar, porém, que antes da aprovação da LAl estavam em vigor a Lei de Responsabilidade Fiscal (LRF) (BRASIL, 2000) e a Lei da Transparência, que também estabeleciam exigências sobre a divulgação de informações por parte do Poder Público. Segundo Raupp e Pinho (2014), a publicação da Lei de Acesso à Informação reforça aos gestores públicos a utilização de meios eletrônicos para divulgação das informações, sendo este meio uma forma de prestar contas das práticas ocorridas na gestão. Neste contexto, para Cavalcanti, Damasceno e Souza Neto (2013, p. 2), "a LAl se propõe em regulamentar o acesso à informação pública no Brasil, com a finalidade de incrementar os meios para que a população possa fiscalizar os instrumentos de controle da gestão".

Desta forma, quanto aos procedimentos previstos na LAl, subordinam-se a eles os órgãos públicos, Cortes de Contas, Judiciário, Ministério Público, autarquias, fundações, empresas públicas, sociedades de economia mista e demais entidades que sejam controladas pela União, Estados, Distrito Federal e Municípios (BRASIL, 2011). No que diz respeito às empresas estatais, elas desempenham funções públicas e privadas, mas, como entidades administrativas, estão em regime público. Tais companhias são criadas por meio de legislação, a fim de fomentar atividade econômica na qual o governo exerce contingência administrativa (BRASIL, 1967). Por esta causa, estão obrigadas a prestar contas para a sociedade e aos órgãos de controle.

Neste contexto, este estudo tem o intuito de responder à seguinte questão: Qual o grau de aderência aos requisitos de transparência e do acesso à informação que as estatais da Região Sul do Brasil apresentam em seus sítios eletrônicos? Sendo assim, o 
objetivo da pesquisa é analisar o grau de aderência aos requisitos de transparência nos sítios eletrônicos das estatais pertencentes aos governos dos Estados da Região sul do Brasil quanto à divulgação das informações.

A compreensão da aderência às exigências estabelecidas pela Lei de Acesso à Informação (LAI) (BRASIL, 2011) e o Decreto 7.724 (BRASIL, 2012) pelos portais eletrônicos das empresas estatais, justifica-se, pois, segundo Gomes (2016), os impactos promovidos pelo acesso informacional vão além das fronteiras acadêmicas, fazendo parte do estabelecimento da sociedade como um todo, bem como da própria condição humana. Para o autor, o livre-acesso às informações garante a participação e direito dos cidadãos de se informar e ser informado, sendo direito primordial do homem, de modo a assegurar não somente o papel do governo, mas também de seu regulamentador.

Dessa forma, a pesquisa auxilia os usuários da informação a verificar quais companhias estatais estão cumprindo o seu dever perante a sociedade no que se refere ao acesso à informação, de modo que possibilite aos cidadãos que exerçam seu direito de acesso informacional. Ainda, a pesquisa promove maior poder de fiscalização dos órgãos reguladores, tendo em vista que permite que seja analisado o nível de transparência das entidades objeto de estudo, por meio de elementos como publicidade, compreensibilidade e utilidade das informações divulgadas, de modo que as ações do governo ante a lacuna e ineficácia da divulgação sejam otimizadas e se mostrem mais incisivas.

O presente estudo baseia-se na pesquisa de Andrade, Raupp e Pinho (2017), na qual se examinou a transparência ativa nos sítios eletrônicos das câmaras dos municípios brasileiros, bem como na pesquisa de Cavalcanti, Damasceno e Souza Neto (2013), que verificou a conformidade das homepages das autarquias federais do Brasil com a Lei de Acesso à Informação. Para isto, foram analisadas 34 estatais localizadas na Região Sul do Brasil, a fim de avaliar se as empresas estatais estão zelando pela observância à LAI, no que diz respeito à divulgação de informações.

\section{REFERENCIAL TEÓRICO}

\section{Transparência no Setor Público}

Tem-se como transparência da Administração Pública o acesso irrestrito a informações que demonstrem o desempenho do setor público de forma oportuna, confiável e completa, disponível gratuitamente em formas e mídias de fácil compreensão do usuário da informação (ARMSTRONG, 2005; KIM et al., 2005). A gestão transparente dos órgãos e entidades do governo assegura ao cidadão o acompanhamento da gestão pública de modo que lhe seja permitida a análise dos procedimentos de seus representantes, contribuindo para o crescimento da cidadania. A transparência e o acesso à informação são direitos da sociedade e a Administração possui o dever de prestar contas, ressaltando que o acesso à informação pública é a regra e o sigilo torna-se a exceção (CGU, 2013).

Considerando que a prestação de contas é um dos elementos básicos da accountability, pode-se relacionar este termo à obrigação dos governantes em prestar contas de suas ações e se responsabilizarem por elas ante a sociedade (ROCHA, 2012). Em vir- 
tude de a divulgação de informações e a prestação de contas das ações governamentais refletirem as decisões tomadas pela Administração Pública, tais decisões têm seu impacto na sociedade, seja de forma direta ou indireta. Para que estes impactos sejam positivos, torna-se necessário que as informações estejam ao alcance do maior número possível de indivíduos, possibilitando a compreensão das informações por parte dos usuários e suscitando o controle social (AGOSTINETO; RAUPP, 2010).

A Constituição Federal de 1988 prevê quanto à garantia da transparência e o acesso à informação, uma vez que todos são iguais perante a lei (BRASIL, 1988). Em promulgação à Constituição Federal (CF), no que se refere à transparência e ao acesso à informação, foram publicadas a Lei de Responsabilidade Fiscal - LRF (BRASIL 2000), a Lei da Transparência (BRASIL, 2009) e a Lei de Acesso à Informação - LAI (BRASIL, 2011).

A divulgação das informações públicas iniciou-se no ano de 2004 com a criação do Portal da Transparência do Poder Público Federal, que objetiva o apoio da correta aplicação dos recursos e o acompanhamento e fiscalização pela sociedade. Outra iniciativa importante neste processo é a criação da divulgação proativa nas páginas de transparência pública em 2005, tendo como foco a divulgação das despesas realizadas pelos órgãos e entidades (CGU, 2013).

\section{Acesso à informação no âmbito das empresas estatais}

A transparência pública, fundamentada no papel exercido pelo governo eletrônico, é importante para a determinação do controle social, sendo os portais eletrônicos o principal canal para a efetiva transparência (CALVOSA; SILVA; KRAKAUER, 2017). Com a Lei de Acesso à Informação (LAI), sancionada pelo governo em 2011, o direito constitucional do acesso à informação para os cidadãos é regulamentado e, com isso, é criada uma área específica nos sítios eletrônicos dos órgãos e entidades para disponibilizar informações que sejam de interesse público, o que proporciona três benefícios: reduz a demanda de solicitação de acesso; minimiza consideravelmente a mão de obra e os custos de processamento e gerenciamento dos pedidos; e possibilita o acesso à informação do cidadão (ALVES, 2012).

No que se refere à disponibilização de informações à sociedade, a LAI representa uma ferramenta fundamental para o exercício da democracia no Brasil, pois ela não só regulamenta o acesso à informação, que anteriormente não estava disponível, como também determina que os governos disponibilizem as informações via internet (RAUPP; ABREU; ABREU, 2015). Em conformidade com o artigo 1ㅇ, itens I e II, as empresas submetidas à Lei de Acesso à Informação são os órgãos públicos da administração do Poder Executivo, Legislativo e Judiciário, incluindo as empresas públicas (BRASIL, 2011).

Com a finalidade de regulamentar as empresas públicas e sociedades de economia mista em suas diretrizes quanto à divulgação das informações e medidas de controle, em 29 de setembro de 2015 a Resolução da Comissão Interministerial de Governança Corporativa e de Administração de Participações Societárias da União (CGPAR) no 5, estabeleceu o dever das estatais em publicar nos sítios eletrônicos uma série de quesitos quanto à: divulgação de estatuto social, missão, visão e valores, fatos relevantes da entidade, composição da Diretoria e Conselhos de Administração, demonstrações financeiras, atualização de informações e demais informações da entidade (BRASIL, 2015) 
A Lei $\mathrm{n}^{\circ}$ 13.303, aprovada em 30 de junho de 2016, dispõe sobre os estatutos jurídicos que regulamentam vários aspectos das empresas estatais com o objetivo de zelar pela transparência das instituições públicas. Esta lei reforça a eficiência, transparência, modelo de governança, condutas ante a disposição de informações para a sociedade e controle das operações, destacando a função social das empresas estatais, bem como a moralidade e a impessoalidade, como as vedações e impedimentos quando na escolha de membros para o Conselho de Administração e diretoria (BRASIL, 2016).

\section{Estudos relacionados}

Cavalcanti, Damasceno e Souza Neto (2013) abordaram os aspectos qualitativos que provam, mediante uma listagem de verificação, a conformidade dos sítios eletrônicos das autarquias federais com a Lei de Acesso à Informação. Os resultados demonstraram o percentual médio de autarquias que cumpriram e descumpriram determinações específicas contidas na LAl; com os resultados obtidos, analisaram se os sítios eletrônicos destas entidades administrativas estão observando as determinações da legislação.

Bento e Bringel (2014) analisaram o comportamento das Empresas Públicas e Sociedades de Economia Mista em razão da sua efetiva subordinação à Lei de Acesso à Informação, tendo em vista os argumentos que estas entidades administrativas apresentam no que se refere ao desenvolvimento da atividade econômica, pois entendem que não precisam guardar total observância às disposições desta lei. Os autores procuraram avaliar o resguardo legal ante a LAI quanto às resistências que tais empresas apresentam em divulgar as informações para os cidadãos. Avaliaram ainda se as empresas estatais estão vinculadas com o compromisso de prestar contas de suas informações, considerando o dever do sigilo, sem, no entanto, evidenciar suas estratégias de negócio.

Andrade, Raupp e Pinho (2017) verificaram a transparência ativa nas homepages das câmaras dos municípios brasileiros com população superior a 200 mil habitantes. A coleta de dados realizou-se nos portais eletrônicos das câmaras e a abordagem do estudo foi qualitativa, utilizando protocolo de observação. O estudo constatou que a transparência ativa ainda não possui completa efetividade em câmaras de municípios brasileiros com grande população, conforme as informações divulgadas nos portais.

\section{PROCEDIMENTOS METODOLÓGICOS}

Em relação à abordagem do problema, a pesquisa classifica-se como quantitativa dada a análise aprofundada das informações divulgadas nos sítios eletrônicos das empresas estatais com sede administrativa no Sul do Brasil, para quantificação de seus respectivos graus de aderências quanto à transparência e o acesso à informação na gestão pública (OLIVEIRA, 2011). Quanto aos objetivos, a pesquisa classifica-se como descritiva, pois tem a finalidade de descrever o nível de aderência à transparência pública apresentado nas homepages das empresas estatais (ALMEIDA, 1996). No que diz respeito aos procedimentos técnicos utilizados, a pesquisa foi classificada como documental, em virtude de a fonte dos dados serem as informações disponibilizadas nos sítios eletrônicos das empresas estatais, considerando estes dados de fonte primária (MARTINS; THEÓPHILO, 2009). 
A amostra deste estudo compreende as empresas estatais localizadas e administradas exclusivamente pelos Estados do Rio Grande do Sul, Santa Catarina e Paraná, completando um conjunto de 34 empresas, sendo 28 de Economia Mista e 6 Empresas Públicas, com análise advinda de pesquisas e coletas de dados nos websites dos seus governos estaduais. Os endereços eletrônicos destas empresas foram localizados a partir de pesquisas no google, realizadas em setembro de 2017. O estudo deteve-se na verificação da disponibilidade da informação para o cidadão, sendo possível analisar a transparência no acesso à informação somente no período atual, utilizando-se do protocolo de pesquisa apresentado no Quadro 1, composto por elementos, parâmetros e indicadores de transparência, adaptado do estudo de Allegretti e Platt Neto (2010) e de Jahns e Raupp (2016).

Quadro 1 - Protocolo de pesquisa

\begin{tabular}{|c|c|c|c|}
\hline Parâmetro & \multicolumn{2}{|r|}{ Indicadores } & Base Legal \\
\hline \multicolumn{4}{|c|}{ Elemento 1 - Publicidade } \\
\hline \multirow{4}{*}{$\begin{array}{l}\text { 1.1. Facilidade de } \\
\text { Acesso aos dados }\end{array}$} & 1 & A página inicial apresenta ferramenta de pesquisa & Art. 8- - LAl \\
\hline & 2 & $\begin{array}{l}\text { O portal eletrônico apresenta diferentes opções de consulta e com } \\
\text { filtros }\end{array}$ & Art. 6o - LAI \\
\hline & 3 & Acessibilidade de conteúdo para pessoas com deficiência & Art. 8 - LAI \\
\hline & 4 & $\begin{array}{l}\text { As consultas podem ser feitas por mês e por exercícios (bimestral, } \\
\text { trimestral, semestral, anual) }\end{array}$ & Art. 6o - LAI \\
\hline \multirow{3}{*}{$\begin{array}{l}\text { 1.2. Qualidade da } \\
\text { navegação }\end{array}$} & 5 & $\begin{array}{l}\text { Banner na página inicial, que dará acesso à seção específica para a } \\
\text { divulgação das informações }\end{array}$ & Art. 70 - DL7724 \\
\hline & 6 & $\begin{array}{l}\text { A maior parte dos links funcionam e quase todas as consultas ofere- } \\
\text { cidas podem ser realizadas }\end{array}$ & Art. 6ㅇ- LAI \\
\hline & 7 & $\begin{array}{l}\text { O portal oferece recursos de acessibilidade, permitindo ao usuário } \\
\text { aumentar ou diminuir o tamanho da fonte }\end{array}$ & Art. 8 - LAl \\
\hline \multirow{4}{*}{$\begin{array}{l}\text { 1.3. Frequência } \\
\text { de atualização das } \\
\text { informações }\end{array}$} & 8 & Relatórios atualizados e publicados em 2017 & Art. 8 - LAI \\
\hline & 9 & Informações e notícias atualizadas há mais de um ano & Art. 8 - LAI \\
\hline & 10 & Informações e notícias atualizadas entre dois meses a um ano & Art. $80-$ LAI \\
\hline & 11 & Informações e notícias atualizadas até um mês & Art. 8ㅇ - LAI \\
\hline \multicolumn{4}{|c|}{ Elemento 2-Compreensibilidade } \\
\hline \multirow{3}{*}{$\begin{array}{l}\text { 2.1. Uso dos recur- } \\
\text { sos que facilitem o } \\
\text { entendimento }\end{array}$} & 12 & $\begin{array}{l}\text { Explicações que facilitem o entendimento sobre a finalidade do } \\
\text { portal (informações gerais da entidade) }\end{array}$ & Art. 60 - LAI \\
\hline & 13 & $\begin{array}{l}\text { Explicação sobre como consultar as informações no portal por meio } \\
\text { de mapa do site }\end{array}$ & Art. 70 - LAI \\
\hline & 14 & Seção com perguntas e respostas & Art. 8 - LAI \\
\hline \multirow{4}{*}{$\begin{array}{l}\text { 2.2. Fornecimento } \\
\text { de Informações } \\
\text { complementares }\end{array}$} & 15 & São sugeridos links para sítios de interesse & $\begin{array}{l}\text { Art. 7ㅇ - DL } \\
7724\end{array}$ \\
\hline & 16 & $\begin{array}{l}\text { Há uma breve explicação sobre controle social/acesso à informa- } \\
\text { ção/transparência }\end{array}$ & Art. 9o - LAl \\
\hline & 17 & Disponibiliza glossário com termos utilizados pelas entidades & Art. 70 - LAI \\
\hline & 18 & Disponibiliza na homepage endereço de redes sociais & Art. 70 - LAI \\
\hline \multirow{4}{*}{$\begin{array}{l}\text { 2.3. Interação com } \\
\text { usuários }\end{array}$} & 19 & Disponibiliza fórum para usuários & Art. 8 - LAI \\
\hline & 20 & Informa ouvidoria e telefone para contato & Art. $80-$ LAI \\
\hline & 21 & Informa endereço e horários de atendimento & Art. 8ㅇ - LAI \\
\hline & 22 & Informa e-mail para contato & Art. 80 - LAI \\
\hline \multicolumn{4}{|c|}{ Elemento 3 - Utilidade da Informação } \\
\hline \multirow{4}{*}{$\begin{array}{l}\text { 3.1. Disponibiliza } \\
\text { informações de } \\
\text { transparência das } \\
\text { entidades }\end{array}$} & 23 & $\begin{array}{l}\text { Informação no portal sobre repasses ou transferências de recursos } \\
\text { financeiros }\end{array}$ & Art. 80 - LAI \\
\hline & 24 & $\begin{array}{l}\text { Informações sobre o acompanhamento de programas, ações, pro- } \\
\text { jetos e obras }\end{array}$ & Art. $80-$ LAI \\
\hline & 25 & $\begin{array}{l}\text { Informação sobre a gestão do patrimônio público (conselho de } \\
\text { administração, diretoria, membros, etc.) }\end{array}$ & Art. $80-$ LAI \\
\hline & 26 & Divulgação das Demonstrações Financeiras & Art. 70 - LAI \\
\hline
\end{tabular}




\begin{tabular}{|c|c|c|c|}
\hline \multirow{4}{*}{$\begin{array}{l}\text { 3.2. Disponibiliza } \\
\text { dados para down- } \\
\text { load e pedido de } \\
\text { acesso à informa- } \\
\text { ção }\end{array}$} & 27 & $\begin{array}{l}\text { Download de documentos em todos os formatos para facilidade de } \\
\text { análise da informação }\end{array}$ & Art. $80-$ LAI \\
\hline & 28 & Download de documentos em Excel & Art. $80-$ LAI \\
\hline & 29 & Download de documentos em PDF e/ou documento de texto & Art. $80-$ LAI \\
\hline & 30 & $\begin{array}{l}\text { Apresenta ícone para solicitação de acesso à informação e acompa- } \\
\text { nhamento do pedido }\end{array}$ & Art. $10-$ LAI \\
\hline \multirow{2}{*}{$\begin{array}{l}\text { 3.3. Disponibiliza } \\
\text { informações sobre } \\
\text { procedimentos lici- } \\
\text { tatórios, convênios } \\
\text { e contratos }\end{array}$} & 31 & $\begin{array}{l}\text { Apesenta informações sobre processos licitatórios de período atual } \\
\text { e anteriores }\end{array}$ & Art. 8 - - LAI \\
\hline & 32 & $\begin{array}{l}\text { Apesenta informações completas sobre processos licitatórios com } \\
\text { possibilidade de download dos dados }\end{array}$ & Art. $80-$ LAI \\
\hline
\end{tabular}

Fonte: Elaborado a partir de Allegretti e Platt Neto (2010) e Jahns e Raupp (2016).

Para estabelecer o grau de aderência à transparência e ao acesso à informação dos portais eletrônicos das empresas estatais, foi atribuído a cada indicador peso de zero a 2, que foi aplicado em cada item do protocolo de pesquisa, conforme as constatações nos sítios eletrônicos. Para cada peso estão vinculados critérios que foram evidenciados pelos indicadores na coleta dos dados, como descrito no Quadro 2. Para isso, utilizou-se como base o modelo da análise de aderência do estudo de Dias (2016).

Quadro 2 - Modelo de análise da aderência ao acesso à informação

\begin{tabular}{|c|c|}
\hline $\begin{array}{c}\text { Peso } \\
0\end{array}$ & $\begin{array}{l}\text { Indicadores de Aderência } \\
\text { Omitido: quando o indicador não é apresentado ao usuário do portal eletrônico }\end{array}$ \\
\hline 1 & $\begin{array}{l}\text { Aderência Parcial: quando apenas parte da informação solicitada é apresentada } \\
\text { pela população }\end{array}$ \\
\hline 2 & $\begin{array}{l}\text { Aderência Plena: Quando todas as informações requeridas foram devidamente } \\
\text { fornecidas pela população }\end{array}$ \\
\hline
\end{tabular}

Fonte: Elaborado a partir de Dias (2006).

Após atribuição dos pesos para cada indicador, foi possível aplicar o cálculo do grau de aderência utilizando média aritmética a partir do peso máximo atribuído para uma aderência plena e, então, se dividiu este valor pelos pesos que cada portal eletrônico atingiu depois de aplicados os indicadores. Para a definição dos percentuais médios, foi calculado o desvio padrão das médias aritméticas de cada elemento de transparência, a fim de descrever a variação e os intervalos entre os percentuais de classificação do conjunto da população. Foi apurado o desvio para baixo que resultou da subtração da média aritmética e o desvio padrão. O resultado é o percentual de intervalo considerado como baixa aderência. $O$ cálculo do desvio para cima é a soma da média aritmética e o desvio padrão. Este é o intervalo de percentuais que representaram alta aderência. O método de cálculo e classificação do grau de aderência utilizado baseou-se no estudo de Machado, Victor e Matts (2016), sendo o grau de aderência classificado como baixo, médio e alto.

\section{ANÁLISE DOS DADOS}

\section{Análise do elemento publicidade}

O objetivo desta seção é apresentar o primeiro elemento de transparência pública: a publicidade. A partir da aplicação do protocolo de pesquisa, resultando nos percentuais médios de aderência para cada indicador, foi possível obter o Gráfico 1, que apresenta os resultados encontrados para os indicadores deste primeiro elemento, itens 1 a 11 . 
Gráfico 1 - Índices de conformidade à publicidade

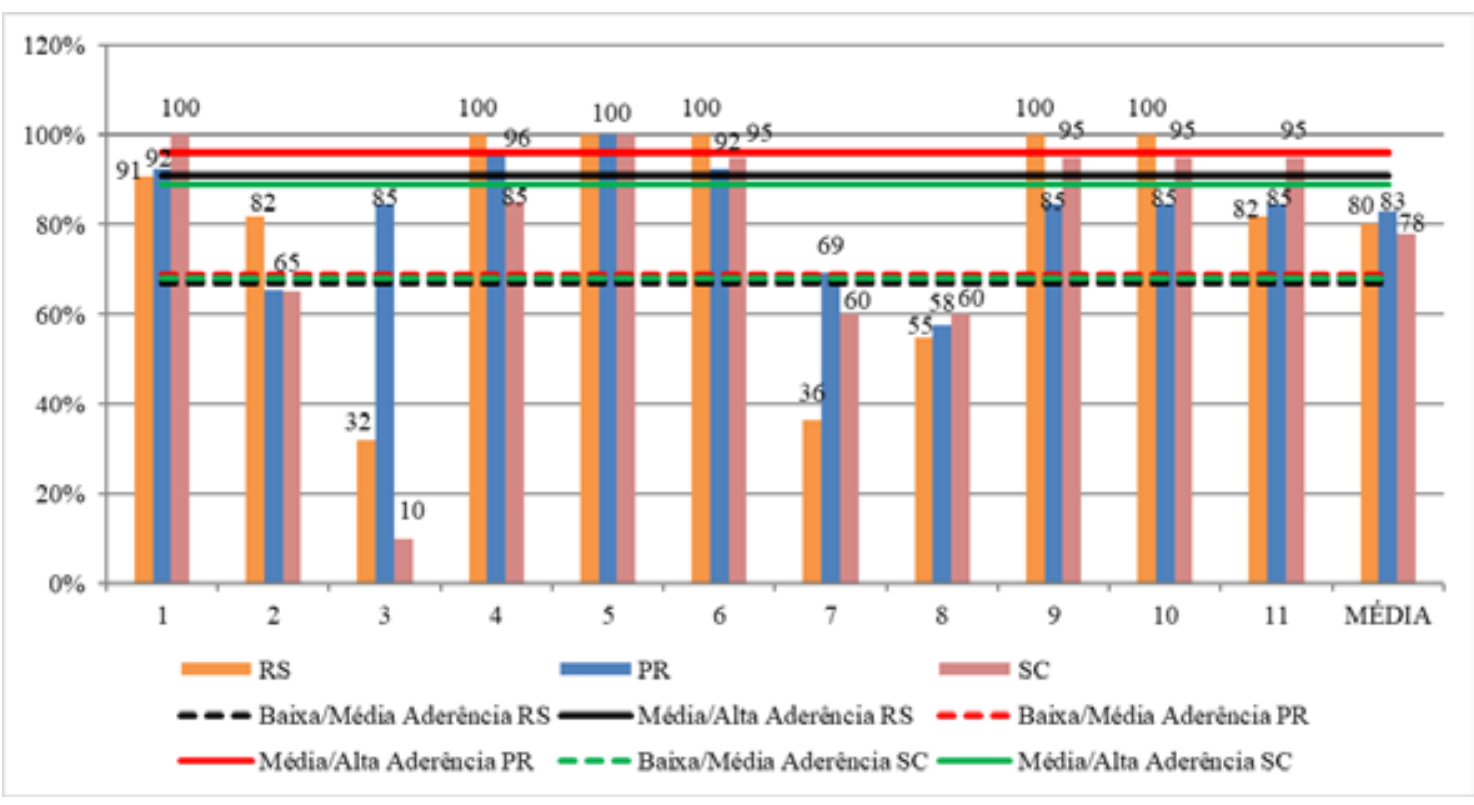

Fonte: Elaborado a partir dos dados da pesquisa (2017).

Com o Gráfico 1 é possível verificar que os percentuais médios de aderência foram de $80 \%, 83 \%$ e $78 \%$ para os sítios eletrônicos das estatais do Rio Grande do Sul, Paraná e Santa Catarina, classificando os três Estados em grau médio de aderência. Os percentuais considerados como de médio grau de aderência variam entre 69\% e 91\% para as estatais do Rio Grande do Sul. Já os percentuais abaixo de 69\% classificaram-se como de baixo grau de aderência e os acima de $91 \%$ como de alto grau de aderência. Os portais eletrônicos das estatais do Paraná que atingiram entre $70 \%$ e $96 \%$ se classificaram em médio grau de aderência, e os resultados abaixo de $70 \%$ e acima de $96 \%$ demonstraram, respectivamente, baixa e alta aderência. As estatais de Santa Catarina que obtiveram percentual de $69 \%$ a $89 \%$ se enquadram em médio grau de aderência, e os percentuais abaixo de $69 \%$ e acima de $89 \%$ são, respectivamente, considerados de baixo e alto grau de aderência. Verifica-se que os parâmetros para classificação dos graus de aderência variam entre os Estados, indo de encontro com a pesquisa de Andrade, Raupp e Pinho (2017), que evidenciou que, de modo geral, todos os Estados do Brasil apresentaram resultados de transparência insatisfatórios. Tal resultado pode ser explicado pelo fato de que a quantia de estatais analisadas na presente pesquisa é distinta para cada Estado e, por isso, os resultados podem estar se mostrando enviesados.

O indicador 5 (banner na página inicial) foi o único que teve aderência plena em todos os sítios eletrônicos analisados, e o indicador 3 (acessibilidade do conteúdo para pessoas com deficiência física) apresenta menor aderência para as estatais de Santa Catarina. A partir dos resultados por indicador é possível obter os percentuais médios por parâmetro, demonstrados na Tabela 1. 
Tabela 1 - Elemento publicidade

\begin{tabular}{|l|c|c|c|c|c|c|}
\hline \multirow{2}{*}{ Parâmetro } & \multicolumn{2}{c|}{ Aderência - RS } & \multicolumn{2}{c|}{ Aderência - PR } & \multicolumn{2}{c|}{ Aderência - SC } \\
\cline { 2 - 7 } & $\mathbf{\%}$ & Grau & $\mathbf{\%}$ & Grau & $\mathbf{\%}$ & Grau \\
\hline 1.1. Facilidade de Acesso aos dados & 76 & Médio & 85 & Médio & 65 & Baixo \\
\hline 1.2. Qualidade da navegação & 79 & Médio & 87 & Médio & 85 & Médio \\
\hline 1.3. Frequência de atualização & 84 & Médio & 78 & Médio & 86 & Médio \\
\hline Total - Publicidade & $\mathbf{8 0}$ & Médio & $\mathbf{8 3}$ & Médio & $\mathbf{7 8}$ & Médio \\
\hline
\end{tabular}

Fonte: Elaborada a partir dos dados da pesquisa (2017).

Na Tabela 1 verifica-se que as estatais do Paraná atingiram maior percentual de aderência em relação aos demais Estados, apresentando 83\% e se enquadrando em médio grau de aderência, seguido pelas empresas do Rio Grande do Sul e Santa Catarina, com $80 \%$ e $78 \%$, e também se enquadrando em um médio grau de aderência. Segundo o modelo de análise, são consideradas em um grau médio de aderência as empresas que atendem parcialmente os critérios exigidos pela legislação. Os sítios eletrônicos que apresentaram maior aderência à publicidade pertencem ao Banrisul (RS) e a Celesc (SC), com $100 \%$ de aderência. Já os portais eletrônicos das empresas Cesa (RS) e Compagas (PR) possuem $55 \%$ de aderência à publicidade, mostrando-se os percentuais mais baixos deste elemento.

Quando analisado cada parâmetro, tem-se no parâmetro 1.1 as empresas estatais de Santa Catarina, que apresentaram resultado que Ihes classificou com o menor nível de aderência em comparação com os outros dois Estados, isto porque em seus portais eletrônicos não existe opção de ferramenta de pesquisa e não há orientação para que pessoas com deficiência física possam acessar os dados. No parâmetro 1.2 todas as empresas mantiveram-se em um nível médio de aderência, o que mostra que a qualidade no acesso aos dados não é considerada excelente em todos os aspectos. Sobre o parâmetro 1.3, frequência de atualização das informações, ocorre que os portais que mais atualizam as informações são os pertencentes às estatais de Santa Catarina, com percentual médio de $86 \%$. Este resultado mostra que, mesmo não chegando ao nível máximo de aderência, estas empresas são eficientes na atualização de informações, corroborando os achados de Cavalcanti, Damasceno e Souza Neto (2013), que evidenciaram que mais da maioria das empresas públicas se mostravam transparentes, no entanto ainda existem autarquias que não cumprem com todas as determinações. Dessa forma, evidencia-se que, em uma cultura de acesso à informação, a Administração Pública tem consciência de que a informação pertence ao cidadão e que cabe provê-la de forma tempestiva e compreensível, atendendo de forma eficaz às demandas da sociedade (CGU, 2011).

\section{Análise do elemento compreensibilidade}

Nesta seção são apresentados os resultados em relação ao elemento compreensibilidade. O Gráfico 2 demonstra os resultados obtidos nos indicadores 12 a 22, bem como o percentual médio deste elemento. 


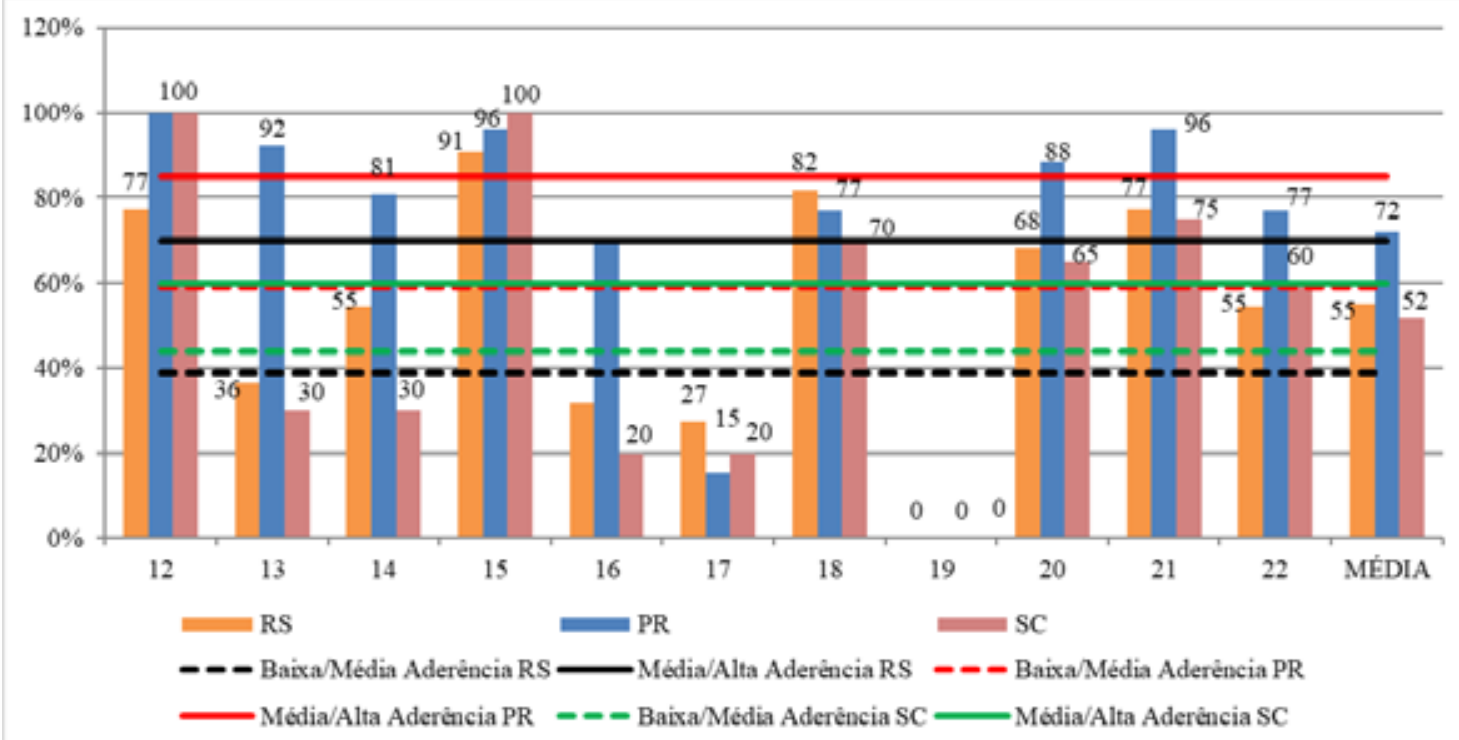

Fonte: Elaborado a partir dos dados da pesquisa (2017).

A partir do Gráfico 2 evidencia-se que as empresas estatais que disseminam e compartilham informações mais compreensíveis estão localizadas no Estado do Paraná, com aderência média de 72\%. Quando analisadas as empresas do Rio Grande do Sul e de Santa Catarina, foi possível verificar que ambas atingiram resultados semelhantes entre si, com média de $55 \%$ e $52 \%$ respectivamente, demonstrando médio grau de aderência para os três Estados analisados no elemento publicidade. Para os indicadores de 12 a 22, foram considerados como de médio grau de aderência os percentuais de $40 \%$ a $70 \%$ para o Rio Grande do Sul, de $60 \%$ a $85 \%$ para o Paraná e de $45 \%$ a $60 \%$ para Santa Catarina, admitindo os percentuais abaixo e acima destas faixas como de baixo e alto grau de aderência.

Com o Gráfico 2 também é possível evidenciar que apenas os indicadores 12 (explicações que facilitem o entendimento sobre a finalidade do portal) e 15 (sugestão de links para sítios de interesse) atingiram aderência plena em 100\%, o que evidencia que todos os portais trazem informações gerais da entidade e sugerem links específicos que direcionam o usuário para outros sítios que são relevantes. É interessante observar que o indicador 19 (fórum para usuários) resultou em $0 \%$ de aderência, posto que em nenhum portal eletrônico foram encontrados fóruns para debate dos usuários. Isto impede que a interação do sítio eletrônico com o usuário seja completa.

Para demonstrar o percentual médio de aderência calculado para os parâmetros vinculados ao elemento compreensibilidade, foi construída a Tabela 2 , apresentada a seguir.

Tabela 2 - Elemento compreensibilidade

\begin{tabular}{|l|c|c|c|c|c|c|}
\hline \multirow{2}{*}{ Parâmetro } & \multicolumn{2}{|c|}{ Aderência - RS } & \multicolumn{2}{c|}{ Aderência - PR } & \multicolumn{2}{c|}{ Aderência - SC } \\
\cline { 2 - 7 } & $\mathbf{\%}$ & Grau & $\mathbf{\%}$ & Grau & $\%$ & Grau \\
\hline $\begin{array}{l}\text { 2.1. Uso dos recursos que facilitem } \\
\text { o entendimento }\end{array}$ & 56 & Médio & 91 & Alto & 53 & Baixo \\
\hline $\begin{array}{l}\text { 2.2. Fornecimento de informações } \\
\text { complementares }\end{array}$ & 58 & Médio & 64 & Médio & 53 & Médio \\
\hline 2.3. Interação com usuários & 50 & Médio & 65 & Médio & 50 & Médio \\
\hline Total - Compreensibilidade & $\mathbf{5 5}$ & Médio & $\mathbf{7 2}$ & Médio & $\mathbf{5 2}$ & Médio \\
\hline
\end{tabular}

Fonte: Elaborada a partir dos dados da pesquisa (2017). 
O parâmetro 2.1 abrange os recursos que proporcionam clareza das informações, evidenciando o alto grau de aderência das estatais do Paraná, com percentual médio de 91\%, uma vez que das 13 estatais localizadas no Estado, 9 aderem em 100\% aos indicadores deste parâmetro, diferentemente dos demais Estados, que obtiveram médio grau de aderência. No Rio Grande do Sul apenas as empresas Banrisul e Corsan apresentaram $100 \%$ de aderência, obtendo nota máxima em todos os indicadores, além de que 4 empresas ficaram abaixo de $39 \%$ de aderência, consideradas com baixo desempenho.

Pode-se observar no parâmetro 2.2 que os três Estados atingiram médio grau de aderência. Constatou-se, portanto, que não existe explicação sobre o controle social e o envolvimento da empresa em promover a transparência no portal eletrônico. Observa-se que não existe glossário na maioria das homepages, dificultando, assim, o controle social do cidadão por falta de entendimento da informação. Das 34 estatais, apenas 7 apresentam glossário, ou seja, um pouco mais de $20 \%$ do total da população analisada.

O parâmetro 2.3 evidencia que a forma mais utilizada para comunicação entre empresa e sociedade é por meio de telefones, e-mail e localização da entidade. Um pouco menos da metade do total das estatais não apresenta ouvidoria, e o Estado do Paraná possui o maior número de estatais que oferecem ouvidoria em seus canais de contatos. Já a disponibilização do endereço de e-mail é uma informação que não tem aderência plena em nenhum dos sítios eletrônicos. No geral, os Estados enquadram-se em médio grau de aderência no parâmetro 2.3, pois cumprem parcialmente os indicadores estabelecimentos que estão em conformidade com a Lei de Acesso à Informação e o Decreto no 7.724/2012, corroborando com Cavalcanti, Damasceno e Souza Neto (2013) e Bento e Bringel (2014).

\section{Análise do elemento utilidade das informações}

Nesta seção é apresentado o elemento utilidade das informações. O Gráfico 3 ilustra os resultados obtidos para os indicadores de 23 a 33 e os graus de aderência.

Gráfico 3 - Índices de conformidade à utilidade das informações

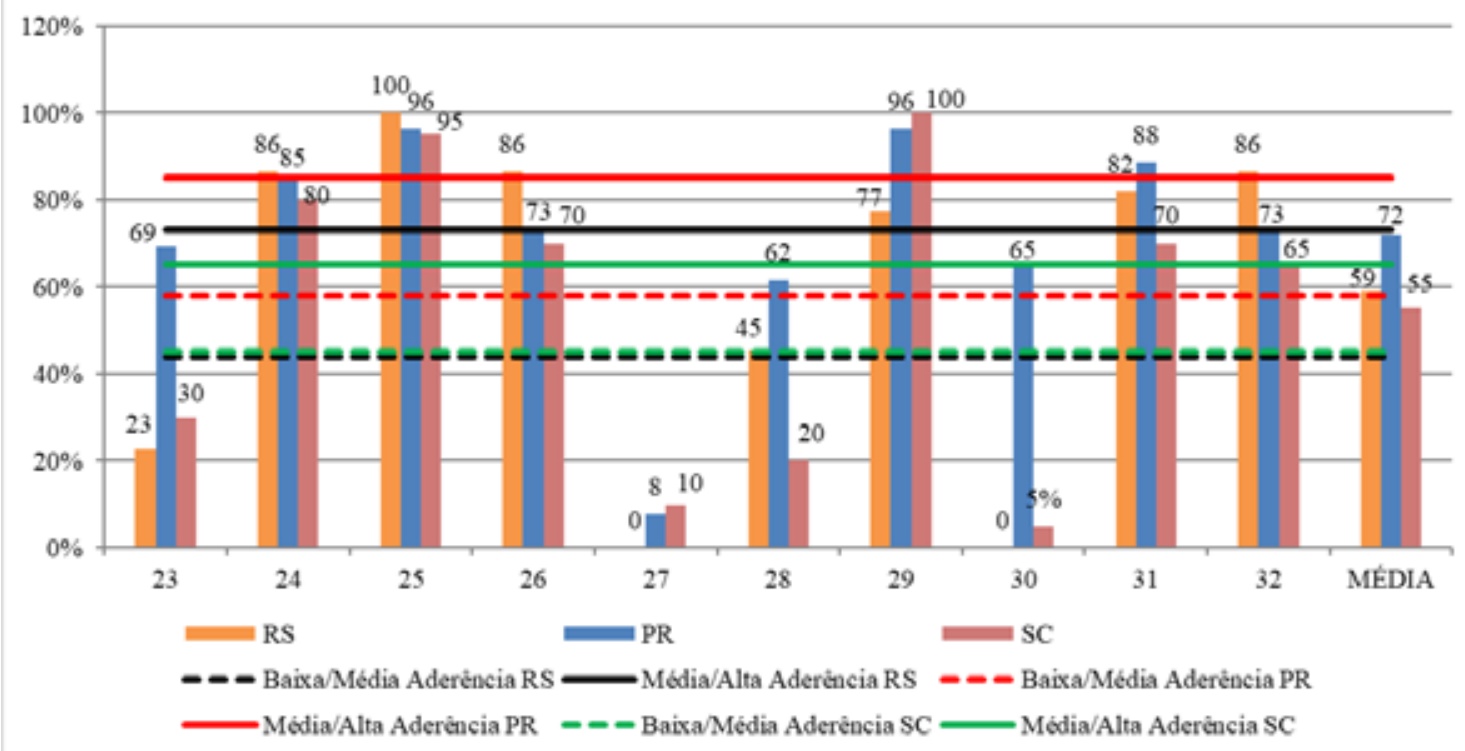

Fonte: Elaborado a partir dos dados da pesquisa (2017). 
De acordo com o Gráfico 3, os indicadores deste elemento apresentaram percentual de aderência de 59\% para as estatais do Rio Grande do Sul, 72\% para as estatais do Paraná e 55\% para as estatais de Santa Catarina. Assim, os sítios eletrônicos do Rio Grande do Sul, que atingiram percentual de $45 \%$ a $73 \%$, classificaram-se como de médio grau de aderência, bem como no Paraná os percentuais de $59 \%$ a $85 \%$ e em Santa Catarina os percentuais de $45 \%$ a $65 \%$ classificaram-se com médio grau de aderência. Os percentuais abaixo destes intervalos são considerados de baixo grau de aderência, e os percentuais acima deste intervalo são considerados de alto grau de aderência.

Ainda, a partir do Gráfico 3, verifica-se que as empresas estatais atingiram percentuais de aderência satisfatórios. As estatais dos três Estados apresentaram melhor desempenho nos indicadores 24 (informações sobre acompanhamento de programas), 25 (informações sobre o patrimônio), 29 (download em PDF) e 31 (informações sobre licitação). Estes indicadores remetem para informações divulgadas sobre a administração da entidade e a possibilidade de o usuário fazer download dos relatórios disponíveis. Nas estatais do Rio Grande do Sul foi constatado $0 \%$ de aderência nos indicadores 27 (download de documentos em todos os formatos) e 30 (ícone para solicitação de acesso à informação). Observa-se, também, que as demais estatais apresentam baixo percentual de aderência para estes indicadores, exceto o Estado do Paraná no indicador 30. A partir disso, verifica-se que $71 \%$ dos portais analisados não apresentam ícones de solicitação de acesso à informação. Logo, no indicador 27 (download de documentos em todos os formatos), apenas 2 empresas estão em conformidade com este indicador.

A Tabela 3 apresenta os resultados encontrados nos parâmetros 3.1, 3.2 e 3.3, juntamente com os resultados finais deste elemento.

Tabela 3 - Elemento utilidade das informações

\begin{tabular}{l|c|c|c|c|c|c}
\hline \multicolumn{1}{c|}{ Parâmetro } & \multicolumn{2}{|c|}{ Aderência - RS } & \multicolumn{2}{c|}{ Aderência - PR } & \multicolumn{2}{c}{ Aderência - SC } \\
\cline { 2 - 8 } & $\mathbf{\%}$ & Grau & $\mathbf{\%}$ & Grau & $\%$ & Grau \\
\hline $\begin{array}{l}\text { 3.1. Disponibiliza informações de trans- } \\
\text { parência }\end{array}$ & 74 & Alto & 81 & Alto & 69 & Alto \\
\hline $\begin{array}{l}\text { 3.2. Disponibiliza dados para download e } \\
\text { pedido de acesso à informação }\end{array}$ & 31 & Baixo & 58 & Baixo & 34 & Baixo \\
\hline $\begin{array}{l}\text { 3.3. Disponibiliza informações sobre } \\
\text { procedimentos licitatórios, convênios e } \\
\text { contratos }\end{array}$ & 84 & Alto & 81 & Médio & 68 & Alto \\
\hline Total - Utilidade das Informações & $\mathbf{5 9}$ & Médio & $\mathbf{7 2}$ & Médio & $\mathbf{5 5}$ & Médio \\
\hline
\end{tabular}

Fonte: Elaborada a partir dos dados da pesquisa (2017).

O terceiro elemento está voltado para a prestação de contas das entidades. Como mencionado no marco teórico, a prestação de contas pode-se relacionar com a obrigação de os entes prestarem contas de suas ações e se responsabilizarem por elas perante a sociedade (ROCHA, 2012). Os dados da pesquisa mostram que as estatais do Estado do Paraná atingiram alto grau de aderência, pois, em comparação aos demais Estados da região Sul, estas apresentaram percentual de $72 \%$ de aderência à prestação de contas. Observou-se que as estatais do Paraná trazem informações completas sobre sua administração (Conselhos, membros, Diretoria, etc.) e se destacam nas divulgações sobre o acompanhamento de programas e projetos. 
No parâmetro 3.1 as estatais do Paraná disponibilizam informações sobre transparência com maior qualidade em relação ao restante da população, destacando-se na divulgação de informações relacionadas à governança corporativa, organograma, estrutura societária, composição acionária, estatuto social, bem como missão, visão e valores. Outro ponto de destaque é a divulgação de projetos e obras. Algumas empresas trazem em planilhas a relação de todos os projetos realizados, outras possuem links de acesso em seus sites que direcionam para os projetos realizados. A maioria são projetos ambientais, culturais e socioeconômicos. Já o acompanhamento de obras é divulgado nas notícias em destaque da empresa. Os três Estados, portanto, classificaram-se com médio grau de aderência, porém Rio Grande do Sul e Santa Catarina com percentuais mais baixos, porque não divulgaram informações sobre repasses e transferência de recursos.

Em relação à divulgação das Demonstrações Financeiras, cabe destacar que, mesmo com a existência de leis que exigem a divulgação dos demonstrativos contábeis pelas entidades públicas, ainda assim há empresas que não estão atentando a esta obrigatoriedade. Das 34 empresas estatais, 4 não divulgam os demonstrativos financeiros, 2 no Estado do Paraná e 2 em Santa Catarina. Cabe ressaltar que, recentemente, foi divulgada a Resolução CGPAR no 5 de 2015, que estabelece para as empresas públicas e sociedades de economia mista a divulgação nos sítios eletrônicos das demonstrações financeiras, devendo permanecer publicadas no mínimo por cinco anos (BRASIL, 2015). Observa-se que todas as estatais do Rio Grande do Sul divulgam seus demonstrativos financeiros, mas apenas o Banrisul, Badesul e CEEE divulgaram os demonstrativos atualizados referentes aos trimestres concluídos em 2017. Em Santa Catarina, as estatais publicaram as demonstrações somente dos últimos três anos. Já no Paraná, cinco estatais divulgam as informações financeiras até o terceiro trimestre de 2017.

No parâmetro 3.2, as empresas do Paraná também se classificaram como mais eficientes na disponibilização de dados para download e acesso à informação. Observou-se que estas disponibilizam download em Excel e PDF, além de que todos os sítios eletrônicos apresentam o link de pedido de acesso à informação com a possibilidade de acompanhamento do pedido. Rio Grande do Sul e Santa Catarina obtiveram baixo grau de aderência neste parâmetro, pois nenhum sítio eletrônico de ambos os Estados apresentou ícone para solicitar acesso à informação, além de que $80 \%$ das estatais de Santa Catarina restringiram o download dos relatórios apenas em PDF e Word, e mais de 50\% das estatais do Rio Grande do Sul não disponibilizaram outras opções de formatos de download a não ser PDF e Word. É importante destacar que nenhum portal eletrônico disponibiliza todos os formatos de documentos para download.

No parâmetro 3.3, as estatais do Rio Grande do Sul são as que mais divulgam informações sobre procedimentos licitatórios, classificando-se em alto grau de aderência com percentual médio de $83 \%$. As estatais de Santa Catarina também se classificaram em alto grau de aderência com percentual médio de $68 \%$ e Paraná em médio grau de aderência com $81 \%$, pois os portais eletrônicos limitam os downloads de editais somente para usuários com cadastrado prévio. 


\section{Análise de conformidade por elemento de transparência}

Nesta seção são apresentados os resultados gerais obtidos na coleta dos dados, considerando todos nos indicadores de transparência analisados nas subseções anteriores. O Gráfico 4 ilustra os resultados gerais de todas as empresas estatais da Região Sul do Brasil.

Gráfico 4 - Índices de conformidade a elemento de transparência

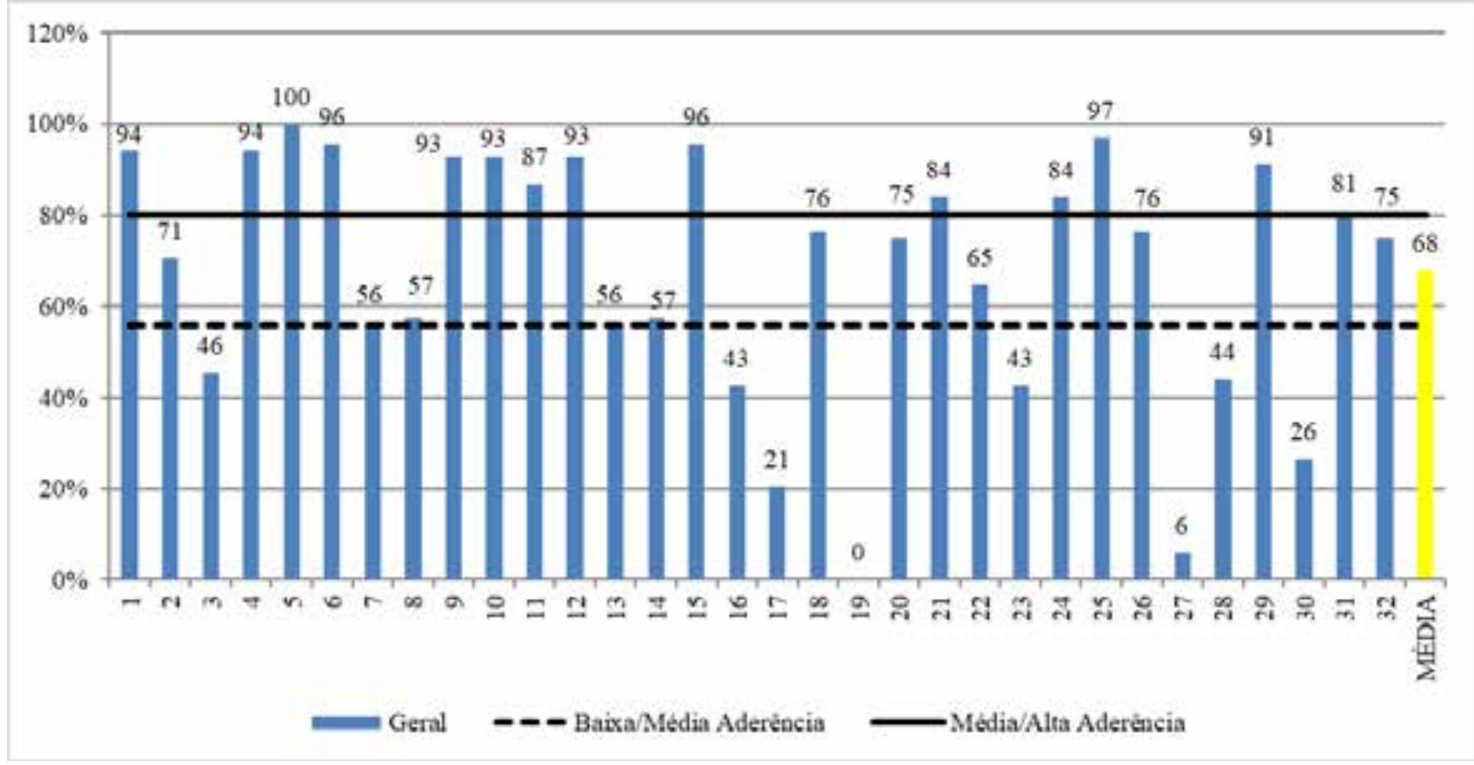

Fonte: Elaborado a partir dos dados da pesquisa (2017).

Os resultados evidenciados no Gráfico 4 demonstram que a média geral das estatais da Região Sul apresentou 68\% de aderência aos requisitos de acesso à informação exigidos pela LAI (BRASIL, 2011). Os percentuais entre $57 \%$ e $80 \%$ foram classificados como de médio grau de aderência. Logo, os indicadores que atingiram resultado abaixo de $57 \%$ se classificaram em baixo grau de aderência, e os acima de $80 \%$ em alto grau de aderência. Com base nos resultados ilustrados no Gráfico 4, o indicador 5 (banner na página inicial) apresentou aderência plena em $100 \%$ nos sítios eletrônicos, o que significa que todos os sites das empresas analisadas estão atentando ao disposto no art. 70, $\S 2$ o, item I do Decreto no 7.724/2012, que especifica o dever das entidades em implementar em seus sítios eletrônicos banner na página inicial que direcione para informações específicas (BRASIL, 2011).

Verifica-se que dos 32 indicadores, 14 deles atingiram alto grau de aderência, 8 apontam um médio grau de aderência e 10 indicadores obtiveram baixo grau de aderência. Com isso, pode-se afirmar que as estatais da Região Sul do Brasil estão em conformidade com as leis que norteiam a transparência e o acesso à informação em quase metade dos indicadores analisados. O indicador 19 (fóruns para usuários) foi o único que não teve aderência, e o indicador 27 (download de documentos em todos os formatos) ficou em segundo lugar com menor percentual de aderência. Verifica-se que poucos indicadores apresentaram baixo grau de aderência, o que mostra que, no geral, as estatais divulgam suas informações em conformidade parcial com a legislação pública. 
Apesar de serem entidades de caráter público e privado, as estatais são entidades administrativas subordinadas à Lei de Acesso à Informação, conforme evidenciado no estudo de Bento e Bringel (2014).

Diante dos dados da pesquisa, entende-se que as estatais que disponibilizam amplo acesso à informação, atingindo melhor grau de aderência, são as estatais do Estado do Paraná, com $76 \%$ de aderência geral, posto que estas apresentam maior destaque nos três elementos de transparência, com $83 \%$ de aderência em publicidade, $72 \%$ em compreensibilidade e $72 \%$ em utilização da informação. As estatais do Rio Grande do Sul aderiram à média de $64 \%$ em relação ao total de indicadores, $76 \%$ no elemento publicidade, 55\% em compreensibilidade e 59\% em utilização da informação. As estatais do Paraná atingiram $62 \%$ no geral de indicadores, $78 \%$ no elemento publicidade, $52 \%$ em compreensibilidade e $56 \%$ em utilidade das informações. No geral, empresas estatais atingiram médio grau de aderência, com resultados mais significativos na publicidade da informação.

A partir dos resultados procedentes da aplicação do protocolo de pesquisa, é possível verificar que o parâmetro 1.1, que compila os indicadores de 1 a 11, apresenta os melhores resultados no atendimento à LAI (BRASIL, 2011) e ao Decreto no 7.724/2012. Embora as estatais estejam obrigadas pela Comissão de Valores Mobiliários (CVM) a seguir determinações sobre transparência, evidencia-se que ainda há dificuldade, por parte dessas empresas, em cumprirem plenamente as leis públicas. Essa problemática também foi encontrada no estudo de Cavalcanti, Damasceno e Souza Neto (2013), o qual mostra que as autarquias encontraram dificuldade em cumprir com itens específicos da Lei de Acesso à Informação.

\section{CONSIDERAÇÕES FINAIS}

Esta pesquisa buscou verificar o grau de aderência à Lei de Acesso à Informação e ao Decreto no 7.724/2012 quanto ao acesso à informação e sua divulgação nos sítios eletrônicos. Foram analisados os websites das empresas estatais localizadas na Região Sul do Brasil que pertencem aos Estados do Rio Grande do Sul, Paraná e Santa Catarina. Os resultados indicam que as estatais localizadas no Paraná apresentam a maior aderência aos indicadores analisados, com 76\%, seguidas pelas estatais do Rio Grande do Sul, com $64 \%$, e pelas estatais de Santa Catarina, com 62\%. No geral, portanto, as empresas públicas e de economia mista classificaram-se em médio grau de aderência, pelo fato de apresentarem variações de percentuais entre os indicadores. Considera-se que as estatais estão cumprindo com a legislação quanto à divulgação da informação em seus portais eletrônicos, porém a aderência plena das exigências da LAI ainda não é realidade em todos os sítios eletrônicos analisados.

Verifica-se que as estatais precisam estar atentas às legislações de âmbito público, conscientes de que devem cumprir os deveres propostos. Mesmo com leis que regulamentam deveres de transparência, ainda existem empresas que acabam não atentando às obrigações próprias de entidades que fazem parte da Administração Pública, o que sugere que deve haver uma maior fiscalização por parte dos órgãos de controle em relação à divulgação da informação, além do controle social que é essencial no monitoramento das atividades. 
A pesquisa apresentou limitações quanto a sua amostra e quanto à norma que rege as estatais. Quanto à amostra, o estudo considerou apenas os Estados da Região Sul do Brasil; sendo assim, o número de estatais estudadas foi reduzido em relação ao total de estatais existentes no Brasil. Outra limitação apresentada é em relação à Lei das Estatais 13.303/2016, que passa a ter vigência imediata a partir de 30 de junho de 2016, conforme seu artigo 97. Seu artigo 91, no entanto, estabelece que as estatais já instituídas nesta data possuem o prazo de 24 meses para se adequarem aos dispostos referidos nesta lei. Nesta pesquisa, portanto, não foi possível avaliar as estatais quanto à aderência e o cumprimento da nova lei, pois as empresas analisadas foram instituídas anteriormente a 30 de junho de 2016 , e no momento da pesquisa ainda estavam dentro do prazo para se adequarem integralmente à lei.

Como sugestão para pesquisas futuras, propõe-se a ampliação da amostra para as empresas estatais dos demais Estados do Brasil. Ainda, cabe estudar as empresas estatais por segmento de operação, analisando a conformidade e a aderência aos novos padrões de Governança, Riscos e Compliance regulamentados pela nova Lei das Estatais $n^{\circ} 13.303 / 2016$. Vale ressaltar que as estatais possuem prazo até junho de 2018 para aplicarem plenamente a lei mencionada. É interessante analisar, todavia, como estas empresas se comportavam antes, durante e depois da obrigatoriedade da Lei $\mathrm{n}$ ㅇ $13.303 / 2016$.

\section{REFERÊNCIAS}

AGOSTINETO, R. C.; RAUPP, F. M. Prestação de contas por meio de portais eletrônicos: um estudo em câmaras municipais da grande Florianópolis. Revista Universo Contábil, Blumenau, v. 6, n. 3, p. 64-79, 2010. ALLEGRETTI, D. dos S.; PLATT NETO, O. A. Funcionalidades, limitações e potencialidades do Portal da Transparência do Estado do Rio Grande do Sul. Revista Catarinense de Ciência Contábil, v. 9, n. 26, p. 7995, 2010.

ALMEIDA, M. L. P. de. Como elaborar monografias. 4. ed. Belém: Cejup. 1996.

ALVES, M. S. Do sigilo ao acesso: análise tópica da mudança de cultura. Revista Tribunal de Contas Estadual de Minas Gerais, Minas Gerais, n. 1, p. 120-134, 2012.

ANDRADE, R. G.; RAUPP, F. M.; PINHO, J. A. G. Em busca da transparência ativa em Câmaras: uma investigação nos maiores municípios brasileiros. Advances in Scientific and Applied Accounting, São Paulo, v. 10, n. 1, p. 3-20, 2017.

ARMSTRONG, E. Integrity, transparency and accountability in public administration: recent trends, regional and international developments and emerging issues. Economic \& Social Affairs. United Nations, 2005. BENTO, L. V.; BRINGEL, P. O. Limites à transparência pública das empresas estatais: análise crítica da aplicação da Lei de Acesso à Informação (Lei no 12.527/2011), a Empresas Públicas e Sociedades de Economia Mista. In: CONGRESSO NACIONAL CONPEDI/UFPB, 23., 2014, João Pessoa. Anais eletrônicos [...]. João Pessoa: Conpedi/UFPB, 2014.

BRASIL. Constituição da República Federativa do Brasil de 1988. Disponível em: http://www.planalto.gov. br/ccivil_03/Constituicao/Constituicao.htm. Acesso em: 14 jun. 2017.

BRASIL. Decreto № 7.724, de 16 de maio de 2012. Regulamenta a Lei № 12.527, de 18 de novembro de 2011. Disponível em: http://www.planalto.gov.br/ccivil_03/_ato2011-2014/2012/decreto/d7724.htm. Acesso em: 15 jul. 2017.

BRASIL. Lei Complementar no 101, de 4 de maio de 2000. Lei de Responsabilidade Fiscal - LRF. Estabelece normas de finanças públicas voltadas para a responsabilidade na gestão fiscal e dá outras providências. Disponível em: http://www.planalto.gov.br/ccivil_03/leis/lcp/lcp101.htm. Acesso em: 14 jun. 2017.

BRASIL. Lei Complementar no 131, de 27 de maio de 2009. Acrescenta dispositivos à Lei Complementar $n$. 101, de 4 de maio de 2000. Disponível em: http://www3.dataprev.gov.br/SISLEX/paginas/43/2009/131. htm. Acesso em: 9 jun. 2017. 
BRASIL. Lei no 12.527, de 18 de novembro de 2011. Lei de Acesso à Informação - LAI. Regula o acesso a informações. Disponível em: http://www.planalto.gov.br/ccivil_03/_ato2011-2014/2011/lei//12527.htm. Acesso em: 14 jun. 2017.

BRASIL. Lei no 13.303, de 30 de junho de 2016. Regula o estatuto jurídico da empresa pública, sociedade de economia mista e de suas subsidiárias. Disponível em: http://www.planalto.gov.br/ccivil_03/_ ato2015-2018/2016/lei/l13303.htm. Acesso em: 20 nov. 2017.

BRASIL. Decreto-lei n. 200, de 25 de fevereiro de 1967. Dispõe sobre a organização da Administração Federal, estabelece diretrizes para a Reforma Administrativa e dá outras providências. Disponível em: http://www.planalto.gov.br/ccivil_03/decreto-lei/del0200.htm. Acesso em: 7 set. 2019.

BRASIL. Ministério do Planejamento, Orçamento e Gestão. Resolução Comissão Interministerial de Governança Corporativa e de Administração de Participações Societárias da União - CGPAR no 5, de 29 de setembro de 2015. Disponível em: http://www.planejamento.gov.br/assuntos/empresas-estatais/legislacao/resolucao. Acesso em: 20 nov. 2017.

CALVOSA, M. V. D.; SILVA, T. A.; KRAKAUER, P. V. C. Portais eletrônicos utilizados nos municípios fluminenses: análise das ações inovadoras. Sociedade, Contabilidade e Gestão, Rio de Janeiro, v. 12, n. 2, 2017.

CAVALCANTI, J. M. M.; DAMASCENO, L. M. S.; SOUZA NETO, M. V. Observância da lei de acesso à informação pelas autarquias federais do Brasil. Revista Perspectivas em Ciência da Informação, Belo Horizonte, v. 18, n. 4, p. 112-126, 2013.

CGU. Controladoria Geral da União. Acesso à Informação Pública: uma introdução à Lei no 12.527 , de 18 de novembro de 2011. Brasília, 2011. Disponível em: http://www.acessoainformacao.gov.br/central-de conteudo/publicacoes/arquivos/cartilhaacessoainformacao-1.pdf. Acesso em: 15 jun. 2017.

CGU. Controladoria Geral da União. Aplicação da Lei de Acesso à Informação na Administração Pública Federal. 2. ed. Brasília: Revista Atualizada e Ampliada, 2016. Disponível em: http://www.acessoainformacao.gov.br/central-de conteudo/publicacoes/arquivos/aplicacao_lai_2edicao.pdf. Acesso em: 15 jun. 2017.

CGU. Controladoria Geral da União. Manual da Lei de Acesso à Informação para Estados e Municípios. 1. ed. Brasília, 2013. Disponível em: http://www.cgu.gov.br/Publicacoes/transparencia-publica/brasil-transparente/arquivos/manual_lai_estadosmunicipios.pdf. Acesso em: 20 jun. 2017.

DIAS, L. N. S. Análise da utilização de indicadores do Global Reporting Initiative (GRI) nos relatórios sociais em empresas brasileiras. 2006. 187 f. Dissertação (Mestrado em Ciências Contábeis) - Faculdade de Administração e Ciências Contábeis, Universidade Federal do Rio de Janeiro, Rio de Janeiro, 2006.

GOMES, A. Lei de Acesso à Informação: o cidadão enquanto sujeito informativo. Revista do Instituto de Ciências Humanas e da Informação, Rio Grande, v. 30, n. 2, 2016.

JAHNS, F. T.; RAUPP, F. M. Transparência do Poder Executivo dos Estados brasileiros. Revista Universo Contábil, Blumenau, v. 12, n. 3, p. 65-72, 2016.

JARDIM, J. M.; MIRANDA, V. L. A implantação da Lei de Acesso à Informação nas Universidades Federais do Estado do Rio de Janeiro. In: CONFERÊNCIA ENANCIB, 16., 2015, João Pessoa. Anais eletrônicos [...]. João Pessoa: Enancib, 2015.

KIM, P. S.; HALLIGAN, J.; CHO, N.; OH, C. H.; EIKENBERRY, A. M. Toward participatory and transparent governance: report on the sixth global forum on reinventing government. Public Administration Review, [s. I.], v. 65, n. 6, p. 646-654, 2005.

MACHADO, V. N.; VICTOR, F. G.; MATTS, J. S. Ativos biológicos: uma análise da aderência ao CPC 29 pelas companhias listadas na BM\&FBOVESPA de 2007 a 2009. Contexto, Porto Alegre, v. 16, n. 34, p. 35-52, 2016.

MARTINS, G. de A.; THEÓPHILO, C. R. Metodologia da investigação científica para ciências sociais aplicadas. 2. ed. São Paulo: Atlas, 2009.

MAZZEI, B. B.; CASTRO, A. L. Governo eletrônico - a transparência no governo do Estado do Paraná. Revista Interdisciplinar de Gestão Social, Bahia, v. 5, n. 3, p. 49-63, 2016.

OLIVEIRA, A. B. S. Métodos da pesquisa contábil. São Paulo: Atlas, 2011.

OLIVEIRA, R. R.; RIBEIRO, S. C. Transparência a partir de portais de governos: uma revisão da literatura. In: CONGRESSO NACIONAL DE EXCELÊNCIA EM GESTÃO CNEG \& O INOVARSE, 11., 2015, Rio de Janeiro. Anais eletrônicos [...]. Rio de Janeiro: CNEG \& O Inovarse, 2015.

RAUPP, F. M.; ABREU, E.; ABREU, M. B. Disponibilização de informações à sociedade em meios eletrônicos: um estudo nas prefeituras dos maiores municípios brasileiros. Revista Catarinense da Ciência Contábil, Florianópolis, v. 14, n. 42, p. 41-54, 2015. 
RAUPP, F. M.; PINHO, J. A. G. de. Construindo a accountability em portais eletrônicos de câmaras municipais: um estudo de caso em Santa Catarina. Cadernos EBAPE.BR, Rio de Janeiro, v. 9, n. 1, p. 117-139, 2011.

RAUPP, F. M.; PINHO, J. A. G. de. Prestação de contas nos portais eletrônicos de Assembleias Legislativas: um estudo após a Lei de Acesso à Informação. Revista Gestão e Planejamento, Salvador, v. 15, n. 1, p. 144161,2014

REICHARD, C. The impact of performance management on transparency and accountability in the public sector. In: HONDEGHEM, A. Ethics and accountability in a context of governance and new public management. Amsterdam: IOS Press, 1998.

ROCHA, H. H. Transparência e accountability no Estado Democrático de direito: reflexões à luz da Lei de Acesso à Informação. Revista Tribunal de Contas Estadual de Minas Gerais, Minas Gerais, n. 1, p. 84-95, 2012. 